\title{
Fasting and postprandial plasma ghrelin levels are decreased in patients with liver failure previous to liver transplantation
}

\author{
Maria Teresa Diz-Lois ${ }^{1}$, Jesús Garcia-Buela ${ }^{4}$, Francisco Suarez ${ }^{1}$, Susana Sangiao- \\ Alvarellos ${ }^{3,5}$, Ovidio Vidal ${ }^{2}$, Fernando Cordido ${ }^{2,3,5}$ \\ ${ }^{1}$ Department of Gastroenterology Hospital A Coruña, A Coruña, Spain \\ ${ }^{2}$ Department of Endocrinology Hospital A Coruña, A Coruña, Spain \\ ${ }^{3}$ Department of Investigation Hospital A Coruña, A Coruña, Spain \\ ${ }^{4}$ Department of Laboratory Hospital A Coruña, A Coruña, Spain \\ ${ }^{5}$ Department of Medicine University of A Coruña, A Coruña, Spain
}

\begin{abstract}
Anorexia is a problem of paramount importance in patients with advanced liver failure. Ghrelin has important actions on feeding and weight homeostasis. Concentrations of ghrelin are controversial in liver cirrhosis. Our aim was to study fasting ghrelin and their response to an oral glucose tolerance test (OGTT) in liver failure patients and normal subjects. Methods We included 16 patients with severe liver failure prior to liver transplantation. As a control group we included 10 age- and BMI-matched healthy subjects. After an overnight fast, $75 \mathrm{~g}$ of oral glucose were administered; glucose, insulin, and ghrelin were obtained at baseline and at times 30, 60, 90, and 120 min, respectively. Results Fasting ghrelin (median and range) were statistically significantly lower for patients compared to the controls, 527 (377-971) pg/ml vs. $643(523-2163) \mathrm{pg} / \mathrm{ml}, P=0.045$, for patients and controls, respectively. The area under the curve for total ghrelin post-OGTT were lower in end-stage liver failure patients than in the control group, 58815 (44730-87420) $\mathrm{pg} / \mathrm{ml} \mathrm{min}$ vs. $76560(56160-206385) \mathrm{pg} / \mathrm{ml} \mathrm{min}$, for patients and controls, respectively, $P=0.027$. Conclusions Ghrelin levels are significantly decreased both fasting and post-OGTT in patients with liver failure candidates for transplantation. Decreased ghrelin levels could contribute to anorexia in patients with cirrhosis.
\end{abstract}

Keywords

Ghrelin; Liver failure; Oral glucose 


\section{Introduction}

Malnutrition is common in patients with liver failure, with a reported prevalence as high as $80 \%$ depending on the severity of liver disease $[1,2]$. The mechanisms of malnutrition in cirrhosis are not completely understood. Both poor dietary intake [2-4] and increased basal energy expenditure have been reported to contribute to a negative energy balance in patients with cirrhosis [1, 5, 6]. Anorexia is a problem of paramount importance in patients with advanced cirrhosis, contributing to malnutrition. The reasons for reduced food intake include hepatocellular failure to tense ascites, causing mechanical difficulties in feeding; poor palatability of a low-sodium diet; and, finally, increased brain tryptophan availability for serotonin synthesis [7]. In turn, malnutrition is a risk factor for the development of lifethreatening complications and increased mortality [8,9], and any effort to promote regular feeding should be encouraged. Malnutrition is of paramount importance in patients with liver failure previous to liver transplantation.

Ghrelin is a 28-amino-acid peptide, predominantly produced by the stomach, which has a unique structure with an $n$-octanoyl ester at its third serine residue, which is essential for its potent stimulatory activity on somatotroph secretion [10-12]. Apart from stimulating GH secretion, ghrelin has other endocrine and nonendocrine actions [13]. Different studies suggest the importance of ghrelin in feeding and weight homeostasis [14-16]. The infusion of ghrelin led to short-term increases in hunger in human subjects [17]. Although obese patients with Prader-Willi syndrome characterized by hyperphagia and obesity have elevated ghrelin levels [18], the concentrations of fasting ghrelin are increased in anorexia and cachexia but reduced in obesity [19-23] and plasma ghrelin levels are negatively correlated with body mass index, body fat mass and plasma leptin, insulin and glucose levels [22, 24, 25]. Insulin resistance has been postulated to play a role in determining the lower fasting plasma ghrelin in the obese [26]. Circulating plasma ghrelin increases before a meal and decreases following the consumption of nutrients and after an oral glucose tolerance test (OGTT) [27-29]. There are two major circulating forms of ghrelin: acyl and des-acyl ghrelin [13]. Acylated ghrelin has proved to be highly relevant in the development of metabolic disturbances, although total ghrelin has a well-established correlation with metabolic disturbances. In fact, most of the leading studies on the correlation between metabolic disturbances and ghrelin have focused on the estimation of total ghrelin [19-23, 27, 28], and there are concerns about the especificity of available acyl-ghrelin assays [30]. We concentrated on measuring total ghrelin, with the aim of comparing our data with the discrepant total ghrelin levels that have been found in hepatic failure patients in different studies [4, 31-35].

Experimental data exists which suggest that ghrelin could protect hepatic tissue. A ghrelin analog, GHRP-2, has a protective effect on the liver in rats that seems to be mediated by IGF-I, TNF-alpha, and nitric oxide. This anti-inflammatory effect of GHRP-2 in the liver is probably exerted on nonparenchymal cells [36]. Ghrelin alleviates biliary obstruction-induced chronic hepatic injury in rats, as a result of its anti-inflammatory and anti-oxidant effects [37]. In contrast to saline, ghrelin treatment ameliorates pancreaticobiliary inflammation and associated remote organ injury in rats [38]. Taking all these data into account, decreased ghrelin levels could be a contributing factor for the deterioration of liver function in cirrhosis. It can be speculated that exogenously administered ghrelin may have an effect against liver failure, as well as to overcome anorexia and protein wasting of patients with cirrhosis.

The basal concentrations of ghrelin have been reported to be deranged in liver cirrhosis, but the results are controversial. Ghrelin levels have been found normal, increased, and decreased in hepatic failure patients [4, 31-35]. The response of ghrelin after an OGTT has not been studied in hepatic failure patients.

Our aim was to study circulating fasting ghrelin levels and their response to an OGTT in liver failure patients prior to liver transplantation and normal control subjects matched for age, sex, and BMI, and their relation with glucose and insulin. 


\section{Results}

The basic characteristics of the patients and healthy control subjects are shown in Table 1 .

Table 1. Basic characteristics in all subjects (median and range)

\begin{tabular}{llll}
\hline & Patients & Controls & $P$ \\
\hline Male/Female & $11 / 5$ & & \\
Age (years) & $54(23-66)$ & $58.5(54-65)$ & Ns \\
BMI (kg/m $\left.{ }^{2}\right)$ & $27.3(18.6-33.7)$ & $25.4(20-29.7)$ & Ns \\
MELD score & $11.5(2.8-20.5)$ & & \\
Child-Pugh score & $9.1(5-12)$ & & \\
Albumin (g/dl) & $3(2.8-3.5)$ & $4.1(3.4-5.3)$ & 0.001 \\
Bilirubin (mg/dl) & $2.9(0.5-12.7)$ & $0.5(0.4-0.9)$ & 0.001 \\
Etiology & & & \\
Alcoholic & 7 & & \\
Viral & 5 & & \\
Hepatocellular carcinoma & 3 & & \\
PBC & 1 & & \\
\end{tabular}

$B M I$ body mass index

$M E L D$ model for end-stage liver disease

$P B C$ primary biliary cirrhosis

$N s$ non significant

\section{Fasting serum levels}

Fasting glucose and insulin (median and range) were similar in the end-stage liver failure patients and in the control group, basal glucose $96(62-168) \mathrm{mg} / \mathrm{dl}$ vs. 95 (89-109) $\mathrm{mg} / \mathrm{dl}, P=\mathrm{Ns}$; fasting insulin 8.3 (2.0-27) $\mu \mathrm{U} / \mathrm{ml}$ vs. $5.0(2-12) \mu \mathrm{U} / \mathrm{ml}, P=\mathrm{Ns}$, for patients and controls, respectively. Insulin resistance, as estimated by HOMA scores (median and range), was not statistically different between patients and controls $2.0(0.2-9.6)$ vs. $1.1(0.4-2.7) P=$ Ns, although there was a tendency toward higher levels in the end-stage liver failure group. Fasting GH (median and range) levels were statistically significantly higher in patients than in controls, $2.6(0.2-6.9) \mu \mathrm{g} / \mathrm{l} \mathrm{vs} .0 .2(0.1-0.9) \mu \mathrm{g} / \mathrm{l}, P=0.001$, for patients and controls, respectively. Fasting IGF-I (median and range) levels were statistically significantly lower in patients than in controls, $32(25-112) \mathrm{ng} / \mathrm{ml}$ vs. $87(52-102) \mathrm{ng} / \mathrm{ml}, P=0.008$, for patients and controls, respectively. Fasting ghrelin (median and range) levels were statistically significantly lower in patients than in controls, 527 (377-971) pg/ml vs. 643 (523-2163) pg/ml, $P=0.045$, for patients and controls, respectively. In Fig. 1 we show fasting serum levels (mean values \pm SEM) of ghrelin $(\mathrm{pg} / \mathrm{ml}), \mathrm{GH}(\mu \mathrm{g} / \mathrm{l})$, and IGF-I (ng/ml) in liver failure patients and controls. 

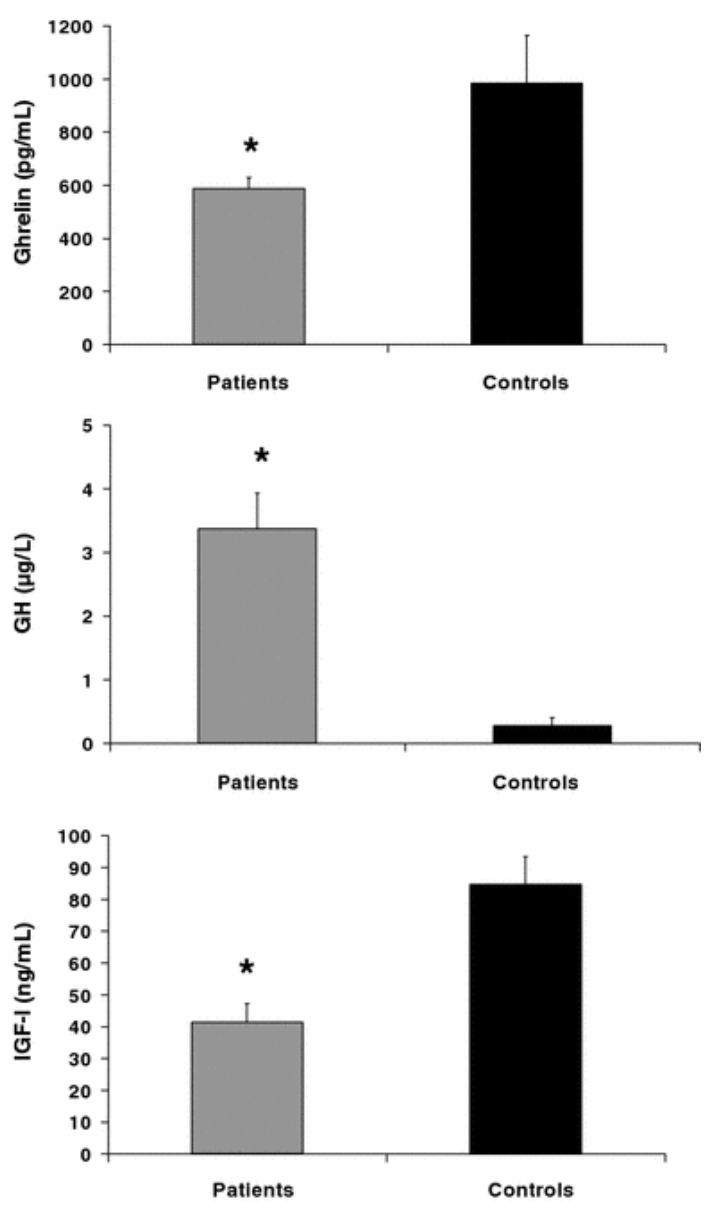

Fig. 1. Fasting serum levels (mean \pm SEM) of ghrelin $(\mathrm{pg} / \mathrm{ml}), \mathrm{GH}(\mu \mathrm{g} / \mathrm{l})$, and IGF-I $(\mathrm{ng} / \mathrm{ml})$ in liver failure patients and controls. * $P<0.01$

Serum levels after oral glucose

Glucose was higher in the end-stage liver failure group than in the control group after the OGTT. At $120 \mathrm{~min}$ after the OGTT, glucose was higher in liver failure patients than in the control group, 236 (93$346) \mathrm{mg} / \mathrm{dl}$ vs. $95(57-164) \mathrm{mg} / \mathrm{dl}$, for patients and controls, respectively, $P=0.001$. The area under the secretory curve (AUC) of glucose were statistically significant higher in patients than in controls, 23955 (16530-39615) mg/dl min vs. 14775 (12030-20805) $\mathrm{mg} / \mathrm{dl} \mathrm{min}$, for patients and controls, respectively, $P=0.001$. Insulin levels were not statistically different between the two groups at any point of the curve. The AUC of insulin were not statistically significant different between patients and controls, 5533 (194518318) $\mu \mathrm{U} / \mathrm{ml} \min$ vs 4107 (2068-12441) $\mu \mathrm{U} / \mathrm{ml} \mathrm{min}$, for patients and controls, respectively, $P=$ Ns. Figure $2 \mathrm{a}$ and $\mathrm{b}$ show serum glucose and insulin levels (mean values \pm SEM) in end-stage liver failure group and normal subjects during the OGTT. 

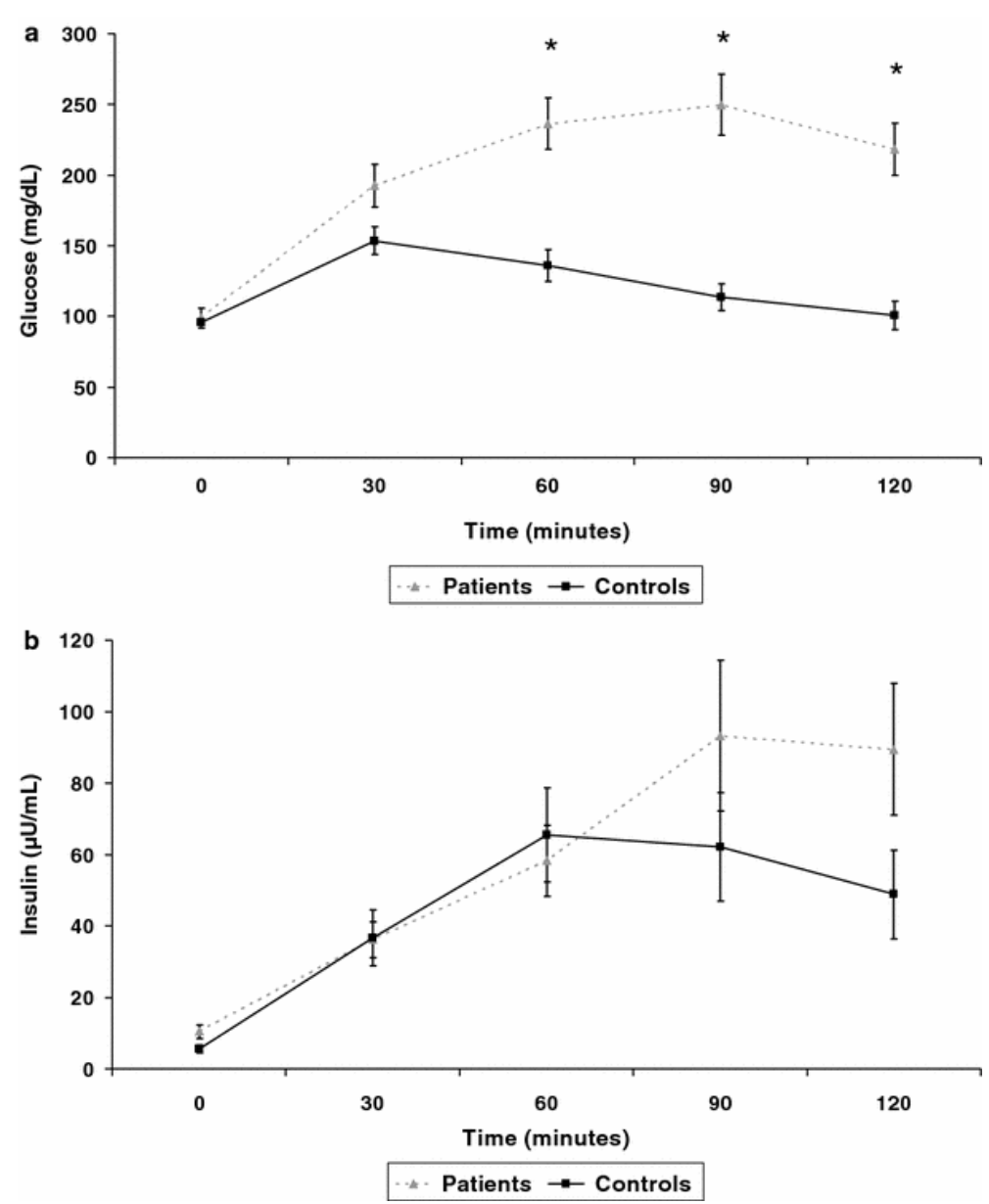

Fig. 2. a Mean \pm SEM plasma glucose $(\mathrm{mg} / \mathrm{dl})$, in liver failure patients and controls during the oral glucose tolerance test. $* P<0.01$ between patients and controls at that time point. b Mean \pm SEM serum insulin levels $(\mu \mathrm{U} / \mathrm{ml})$ in liver failure patients and controls during the oral glucose tolerance test

Ghrelin levels decreased during the OGTT, and nadir ghrelin levels were statistically lower than fasting total ghrelin levels for both patients and controls; patients: 527 (377-971) pg/ml vs. 441 (318$626) \mathrm{pg} / \mathrm{ml}$, for fasting and nadir ghrelin, respectively, $P=0.001$; controls: $643(523-2163) \mathrm{pg} / \mathrm{ml} \mathrm{vs} .567$ (442-1154) $\mathrm{pg} / \mathrm{ml}$, for fasting and nadir ghrelin, respectively, $P=0.008$.

Ghrelin was lower in the end-stage liver failure group than in the control group after the OGTT. Nadir ghrelin levels were lower in end-stage liver failure patients than the control group, 441 (318-626) pg/ml vs. 567 (442-1154) pg/ml, for patients and controls, respectively, $P=0.02$. The median (range) reduction in total ghrelin levels during the OGTT was not different between the two groups, 100 (26-448) pg/ml vs. $150(0-1009) \mathrm{pg} / \mathrm{ml}$ for patients and controls, respectively; $P=\mathrm{Ns})$. The AUCs of total ghrelin were lower in end-stage liver failure patients than in the control group, 58815 (44730-87420) pg/ml min vs. $76560(56160-206385) \mathrm{pg} / \mathrm{ml} \mathrm{min}$, for patients and controls, respectively, $P=0.027$. Figure 3 shows serum ghrelin levels (mean values \pm SEM) in end-stage liver failure patients and normal subjects during the OGTT. In Table 2 we show fasting and post-OGTT biochemical and hormonal data (median and range) in patients and controls. 


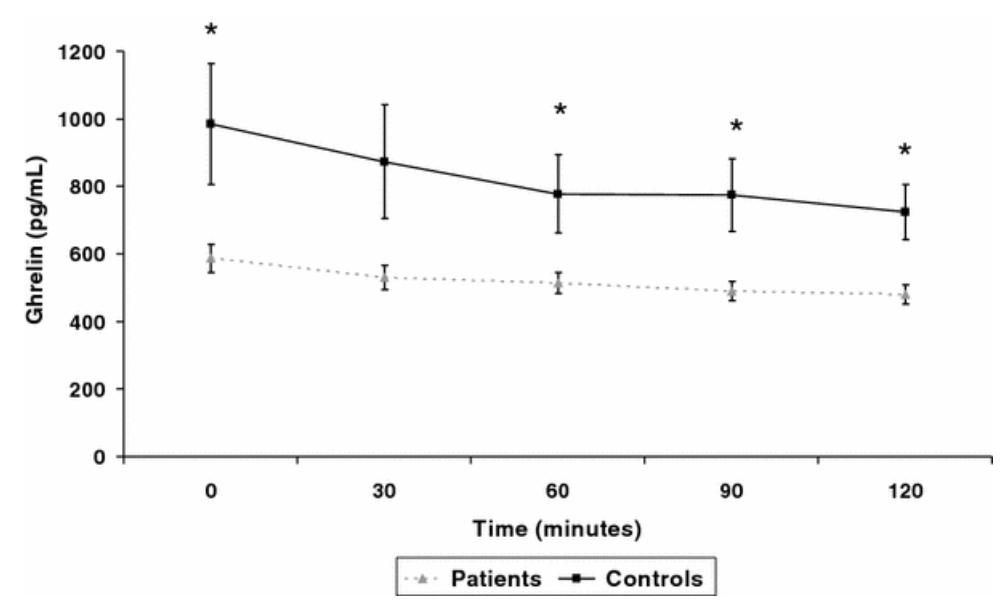

Fig. 3. Mean \pm SEM serum ghrelin levels $(\mathrm{pg} / \mathrm{ml})$ in liver failure patients and controls during the oral glucose tolerance test. ${ }^{*} P<0.05$ between patients and controls at that time point

Table 2. Fasting and after an OGTT biochemical and hormonal data (median and range) in patients and controls

\begin{tabular}{lccc}
\hline & Patients & Controls & $P$ \\
\hline & & & Ns \\
Fasting glucose & $96(62-168)$ & $95(89-109)$ & 0.001 \\
Glucose after OGTT & $236(93-346)$ & $95(57-164)$ & Ns \\
Fasting insulin $(\mu \mathrm{HI} / \mathrm{ml})$ & $8.3(1.0-26.7)$ & $5.1(2.0-12.0)$ & Ns \\
HOMA & $2.0(0.2-9.6)$ & $1.1(0.4-2.7)$ & 0.001 \\
GH $(\mu \mathrm{g} / \mathrm{l})$ & $2.6(0.2-6.9)$ & $0.2(0.1-0.9)$ & 0.008 \\
IGF-I $(\mathrm{ng} / \mathrm{ml})$ & $32(25-112)$ & $87(52-102)$ & 0.045 \\
Fasting ghrelin $(\mathrm{pg} / \mathrm{ml})$ & $527(377-971)$ & $643(523-2163)$ & 0.02 \\
Nadir ghrelin $(\mathrm{pg} / \mathrm{ml})$ & $441(318-626)$ & $567(442-1154)$ & 0.027 \\
AUC ghrelin $(\mathrm{pg} / \mathrm{ml} \mathrm{min)}$ & $58815(44730-87420)$ & $76560(56160-206385)$ & \\
\end{tabular}

HOMA homeostasis model assessment

$A U C$ area under the secretory curve

Glucose after OGTT 120 min glucose after oral glucose tolerance test

Ns non significant

\section{Correlations}

Although the number of patients for the correlation studies was small, we analyzed if there was significant correlation between fasting ghrelin levels and age, BMI, IGF-I, fasting glucose, glucose at any point during the OGTT, basal GH, fasting insulin, insulin at any point during the OGTT, insulin resistance as estimated by HOMA, glucose peak, insulin peak, glucose AUC, and insulin AUC. In the group of liver failure patients, fasting total ghrelin levels negatively correlated with basal GH $(r=-0.626$; $P=0.02$ ) (Fig. 4). We were unable to discover any other significant correlation. 


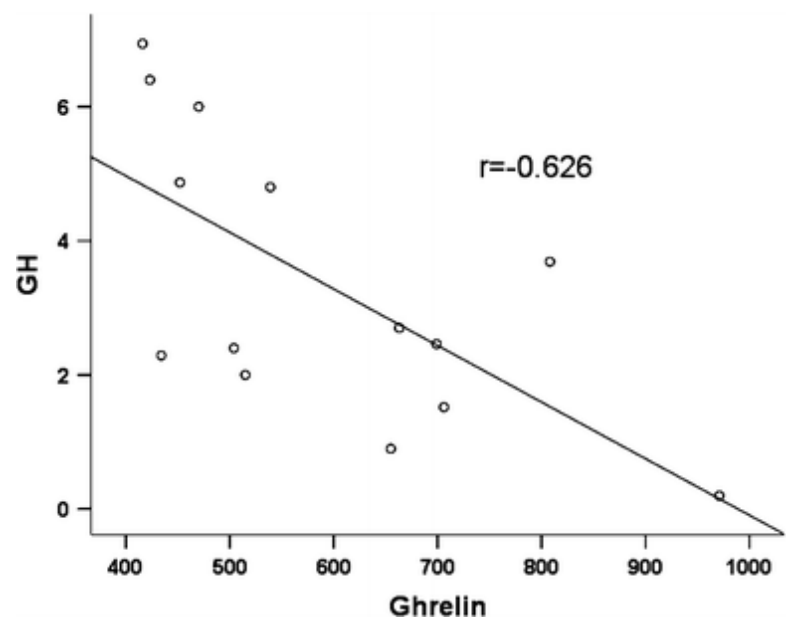

Fig. 4. Fasting total ghrelin $(\mathrm{pg} / \mathrm{ml})$ and fasting $\mathrm{GH}(\mu \mathrm{g} / \mathrm{l})$ levels correlation in liver failure patients $(r=-0.626 ; P=0.02)$

We studied the correlation between the degree of reduction of total ghrelin levels during the OGTT and age, BMI, IGF-I, fasting glucose, glucose at any point during the OGTT, basal GH, fasting insulin, insulin at any point during the OGTT, insulin resistance as estimated by HOMA, fasting total ghrelin levels, glucose peak, insulin peak, glucose AUC, and insulin AUC. In the group of liver failure patients, the degree of reduction in ghrelin levels negatively correlated with BMI $(r=-0.556 ; P=0.03)$ (Fig. 5). With regard to this correlation, if we exclude the patient with the greatest reduction in ghrelin there is still an important correlation $(r=-0.482)$, although the results are borderline non-significant $(P=0.069)$. We believe that the loss of significance is due to our relatively small number of patients, although that there is no reason to exclude the data for this patient, as it is similar in clinical and analytical terms to the general patient group. We were unable to discover any other significant correlation.

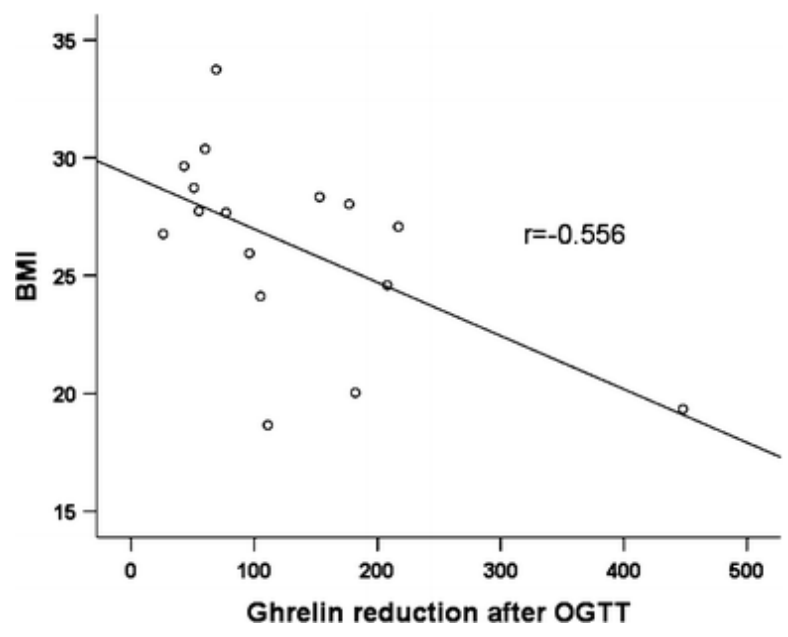

Fig. 5. Degree of reduction in ghrelin $(\mathrm{pg} / \mathrm{ml})$ levels after an oral glucose tolerance test (OGTT) and body mass index (BMI) correlation in liver failure patients $(r=-0.556 ; P=0.03)$ 


\section{Discussion}

We have found significantly decreased plasma levels of ghrelin both fasting and post-OGTT in endstage liver failure patients candidates for transplantation when compared with control subjects. Furthermore, ghrelin levels were similarly suppressed after glucose ingestion in patients with liver failure candidates for transplantation.

During its synthesis, ghrelin is acylated on serine-3 with an esther-linked fatty acid group [39, 40]. This acylation is essential for the activity of ghrelin at the GH secretagogue receptor [10, 41] and probably for its orexigenic actions. However, des-acyl ghrelin has multiple biologic activities [42, 43, 44, $45,46,47]$. One limitation of our study is that we did not measure acyl ghrelin, although there are concerns about the especificity of available acyl-ghrelin assays [30]. In the classic studies, total ghrelin levels increase preprandially and drop rapidly after meals, suggesting that total ghrelin plays a role in short-term regulation of food intake [28, 48]. Recent data from Thorner's group have shown, in men, that under postprandial conditions ghrelin and des-acyl ghrelin levels changed in parallel, with sharp declines after feeding both during normal and experimental feeding [49]. In contrast, under fasting conditions the balance of ghrelin to des-acyl ghrelin was altered, with acyl-ghrelin levels near the nadirs observed on the fed day [50]. This data could raise some concerns about the orexigenic properties of acyl-ghrelin under fasting conditions, and confirm that under postprandial conditions total ghelin and acyl-ghrelin change in parallel. The total ghrelin data from the current study allow us to compare these results with the discrepant total ghrelin levels that have been found in hepatic failure patients in different studies [4, 31, $32,33,34,35]$.

Fasting total ghrelin levels have been studied in hepatic failure patients, with increased ghrelin levels found in some studies [32, 35]. Atavesen et al. [32] found that in cirrhosis serum ghrelin levels were increased with a corresponding decrease in serum leptin concentrations. The increase of ghrelin was more prominent in Child $\mathrm{C}$ cirrhosis and the level was correlated with TNF-alpha. Tacke et al. [35] found that ghrelin was significantly elevated and IGF-1 reduced in chronic liver disease patients compared with healthy controls. IGF-1 serum levels inversely correlated with Child's classification. Ghrelin levels were significantly elevated in Child C cirrhosis patients regardless of the etiology of liver disease. Ghrelin levels did not correlate with liver function. Normal ghrelin levels have been found in other studies [4, 31, 33]. Kalaitzakis et al. [31] found that patients with cirrhosis had similar fasting ghrelin levels to a control group. In contrast, patients with cirrhosis had higher postprandial glucose and lower ghrelin concentrations at $4 \mathrm{~h}$ postprandially than the control subjects. In the study by Takahashi et al. [33], plasma ghrelin levels were slightly but not significantly elevated in patients with liver cirrhosis when compared with controls. Plasma ghrelin levels were significantly correlated with BMI, but not with the severity of liver damage. In the study by Marchesini et al. [4], ghrelin levels were not increased in cirrhosis but increased with decreasing Corli score, a method used to quantitate and score the amount of ingested food, and along the scale of anorexia/hunger. Similarly to our results, although in patients with primary biliary cirrhosis, Breidert et al. [34] found that serum ghrelin levels were decreased compared to the control group. In the current study, we found decreased fasting and post-OGTT ghrelin in patients with cirrhosis candidates for transplantation.

Discrepancies between the different studies, including our own, could at least be partly explained by different patient selection, control subject selection, or both. The different causes of cirrhosis with a wide range of insulin sensitivity could have an impact on total ghrelin levels. Some of the patients in the different studies had a wide range of hepatocellular dysfunction and were not BMI-matched with control subjects. In the current study, all patients were liver failure patients candidates for transplantation and BMI-matched control subjects were chosen. However, due to the hepatocellular dysfunction and the heterogeneous nature of liver failure patients, our study patients were not perfectly matched with the control group, for example GH, IGF-I, and postprandial glucose were all different. In nonalcoholic fatty liver disease, ghrelin levels have been found decreased and correlated with insulin resistance [51]; in contrast with those patients with normal liver function, in the current study the severity of liver damage was advanced. Nevertheless, both studies suggest that in liver disease ghrelin levels are decreased, although probably through different mechanisms.

To our knowledge, only one study exists of postprandial ghrelin levels in liver cirrhosis. Similarly to our results, the patients with cirrhosis had lower ghrelin concentrations at $4 \mathrm{~h}$ postprandially than the control subjects, although fasting ghrelin levels were similar to the control subjects [31]. In normal subjects there is a decrease in ghrelin levels after the OGTT [27]. The response of post-OGTT ghrelin 
levels in hepatic failure patients was similar to the control group, in both groups ghrelin levels decreased during the OGTT, and nadir ghrelin levels were statistically lower than fasting total ghrelin levels for both patients and controls.

The mechanisms of altered fasting or postprandial ghrelin response might involve glucose, insulin, $\mathrm{GH}$, or all three. Insulinemia is essential for postprandial ghrelin suppression with glucose having an additional effect $[52,53,54]$. Therefore, insulin resistance resulting in high postprandial glucose and insulin might be involved in the low ghrelin observed post-OGTT. A clearly negative association between ghrelin and insulin secretion has been found in humans, as well as in animals by the majority of authors [20, 28, 54], although not by all [55, 56]. Ghrelin is a potent stimulus for GH secretion [13, 29] and, at least under certain physiologic conditions, ghrelin modulates the regulation of GH secretion [57], although the relationship between ghrelin and GH secretion is controversial. In acromegaly, a pathophysiological model of increased GH secretion, some studies have found normal ghrelin levels [58, 59, 60, 61], while others have found decreased ghrelin levels in patients with acromegaly [62, 63, 64], suggesting that increased GH could contribute towards the decreased ghrelin levels in a classic feedback manner. This said, the number of patients used in the correlation studies was small, and the results should be taken with caution. In the current study, fasting total ghrelin levels negatively correlated with basal GH in patients with liver failure, suggesting that increased GH could contribute to the decreased fasting ghrelin levels. In line with other studies [65], this data supports the hypothesis that GH feedback inhibits ghrelin secretion. In liver failure patients, we found decreased IGF-I and increased GH. IGF-I is the main circulating inhibitory factor for GH secretion [61, 62, 63]. However, we could not find a significant correlation between ghrelin and IGF-I. An alternative explanation for the association between ghrelin and $\mathrm{GH}$, could be that it is indirectly due to a relationship between ghrelin and IGF-I. In the current study, the degree of reduction in ghrelin levels negatively correlated with BMI in patients with liver failure, in accordance with the important influence of nutritional status on ghrelin regulation $[19,20,21,22,23,27$, 66]. Although a small patient sample was used in this study, we could not find significant correlation between fasting ghrelin and the degree of ghrelin suppression after oral glucose on the one hand and insulin, glucose or IGF-I levels on the other, suggesting that other factors are responsible for fasting ghrelin and the decrease in ghrelin in liver failure patients who are candidates for transplantation. Further studies are needed to clarify the mechanisms responsible for the decrease of ghrelin after oral glucose in liver failure patients.

Ghrelin is the only established circulating orexigenic hormone. Ghrelin enhances appetite and food intake, and its concentration rises preprandially, thereby playing a role in meal initiation. The infusion of ghrelin led to short-term increases in hunger in human subjects [17]. Concentrations of fasting ghrelin are increased in anorexia and cachexia but reduced in obesity [19, 20, 21, 22, 23], probably due to a compensatory mechanism. Disordered circulating ghrelin levels could participate in the altered nutritional status of different clinical situations such as chronic renal failure [67, 68, 69]. The presence of decreased ghrelin levels both fasting and post-OGTT could contribute to the anorexia of patients with advanced liver failure.

In conclusion, we found significantly decreased plasma levels of ghrelin both fasting and post-OGTT between patients with liver failure who were candidates for transplantation and control subjects. Furthermore, ghrelin levels were similarly suppressed after glucose ingestion in patients with liver failure who were candidates for transplantation. These data suggest that decreased ghrelin levels could contribute to the anorexia of patients with advanced cirrhosis. 


\section{Patients and methods}

\section{Patients}

We included 16 patients (11 male, 5 female) with liver failure prior to liver transplantation, median (range) age of 54 (23-66) years, median (range) body mass index (BMI) of $27.3(18.6-33.7) \mathrm{kg} / \mathrm{m}^{2}$. As a control group 10 age and BMI matched healthy or overweight subjects ( 6 male, 4 female), selected from a pool of volunteers available to our unit, were included, median (range) age of 58.5 (54-65) years, median (range) BMI of $25.4(20-29.7) \mathrm{kg} / \mathrm{m}^{2}$.

The diagnosis of liver cirrhosis was established histologically; on the basis of its clinical, laboratory, endoscopic, or imaging features; or both. The severity of liver disease was assessed according to ChildPugh and the Model of End Stage Liver Disease scores. The causes of the liver cirrhosis were as follows: in 7 patients alcohol was the primary cause of the disease; in 5 patients, the cause was viral hepatitis (hepatitis $\mathrm{B}$ in 1 case; hepatitis $\mathrm{C}$ in 4 cases); in 3 patients the cause was hepatocellular carcinoma; in 1 patient the cause was primary biliary cirrhosis. At the time of the study, the patients with alcoholic liver disease had been abstaining from alcohol for 6 months or more. All cases had routine biochemical investigation, an ultrasound scanning of the liver, and a gastrointestinal endoscopy. Among the liver failure prior to liver transplantation patients there were 3 diagnosed of diabetes mellitus prior to the study protocol and were being treated with dietetic therapy. All patients had a markedly suppressed appetite. All patients were ambulatory.

\section{Study procedure}

Between 08.30 and 09.00 a.m., after an overnight fast and while seated, a peripheral venous line was obtained. Fifteen minutes later $75 \mathrm{~g}$ of oral glucose were administered. We obtained blood samples for glucose, insulin, and ghrelin at baseline (fasting) and then at 30, 60, 90, and 120 minutes, respectively. Basal levels of GH and IGF-I were also measured. All blood samples were immediately centrifuged, separated, and frozen at $-80^{\circ} \mathrm{C}$. Samples destined to be used for the determination of plasma ghrelin were specifically retrieved in chilled tubes containing aprotinin and EDTA-Na, and then immediately centrifuged at $4^{\circ} \mathrm{C}$., separated to aliquots and frozen at $-80^{\circ} \mathrm{C}$. The study protocol fulfilled the requirements of the ethical committee of our center and written informed consent was obtained from all patients and controls.

\section{Assays}

Plasma glucose $(\mathrm{mg} / \mathrm{dl})$ was measured with an automatic glucose oxidase method (Roche Diagnostics, Mannheim, Germany). Insulin $(\mu \mathrm{U} / \mathrm{ml})$ was measured with a solid-phase two-site chemiluminescent immunometric assay (Immulite 2000 Insulin, DPC, Los Angeles, CA, USA) and with intrassay coefficients of variation of $5.5 \%, 3.3 \%$, and $3.7 \%$ for low, medium, and high plasma insulin levels, respectively. Serum GH $(\mu \mathrm{g} / \mathrm{l})$ was measured by a solid-phase, two-site chemiluminescent enzyme immunometric assay (Immulite, EURO/DPC) with a sensitivity of $0.01 \mu \mathrm{g} / \mathrm{l}$ and with intrassay coefficients of variation of $5.3 \%, 6.0 \%$, and $6.5 \%$ for low, medium, and high plasma GH levels, respectively. IGF-I (ng/ml) was determined by a chemiluminescence assay (Nichols Institute, San Clemente, CA, USA) and with intrassay coefficients of variation of $4.8 \%, 5.2 \%$, and $4.4 \%$ for low, medium, and high plasma IGF-I levels, respectively. Total ghrelin (pg/ml) was measured by a commercially available radioimmunoassay (RIA) (Linco Research Inc., St Charles, MO, USA), specific for total ghrelin, that uses ${ }^{125}$ I-labeled ghrelin tracer and rabbit antighrelin serum with a specificity of $100 \%$, and with intrassay coefficient of variation between $4.4 \%$ and $10 \%$.

All samples from a given subject were analysed in the same assay run. AUC was calculated by a trapezoidal method. Insulin resistance was calculated on the basis of fasting values of plasma glucose and insulin, according to the homeostasis model assessment (HOMA-IR) method [70] as follows: HOMA$\mathrm{IR}=$ fasting insulin levels $\times$ fasting glucose levels/22.5, where basal insulin levels is in $\mu \mathrm{U} / \mathrm{ml}$, and glucose is in $\mathrm{mmol} / \mathrm{l}$. 


\section{Statistical analysis}

The results are presented as median (range). All comparisons were based on univariate, nonparametric tests. Intragroup comparisons were based on Wilcoxon sign-rank test. Comparisons between patients and controls were based on Mann-Whitney $U$ test. Numerical correlations were analyzed using the Spearman's correlation test. $P$ values $\leq 0.05$ were considered to be significant. For graphic presentation we use mean values \pm SEM. The SPSS software 12.0 (Chicago, IL, USA) was used to produce statistical analysis.

\section{Acknowledgements}

We thank Rosa Nemiña, Ramón Pensado, Iria Brandón, and Sonia Pertega for his technical assistance. Supported in part by: FIS del Instituto de Salud Carlos III PI051024, PI070413 and Red de Grupos RGTO (G03/028, PI050983) and Xunta de Galicia PS07/12, PGIDT05PXIC91605PN, INCITE08ENA916110ES and Redes 2006/27, Spain.

\section{References}

1. O. Selberg, J. Böttcher, G. Tusch, R. Pichlmayr, E. Henkel, M.J. Muller, Identification of high- and low-risk patients before liver transplantation: a prospective cohort study of nutritional and metabolic parameters in 150 patients. Hepatology 25, 652-657 (1997)

2. C. Matos, M.K. Porayko, N. Francisco-Ziller, S. DiCecco, Nutrition and chronic liver disease. J. Clin. Gastroenterol. 35, 391-397 (2002)

3. H.I.M. Davidson, R. Richardson, D. Sutherland, O.J. Garden, Macronutrient preference, dietary intake, and substrate oxidation among stable cirrhotic patients. Hepatology 29, 1380-1386 (1999)

4. G. Marchesini, G. Bianchi, P. Lucidi, N. Villanova, M. Zoli, P. De Feo, Plasma ghrelin concentrations, food intake, and anorexia in liver failure. J. Clin. Endocrinol. Metab. 89, 2136-2141 (2004)

5. J. Ockenga, S.C. Bischoff, H.L. Tillmann, K. Rifai, A. Widjaja, K.H. Böker, M.P. Manns, G. Brabant, Elevated bound leptin correlates with energy expenditure in cirrhotics. Gastroenterology 119, 1656-1662 (2001)

6. A.M. Madden, M.Y. Morgan, Resting energy expenditure should be measured in patients with cirrhosis, not predicted. Hepatology 30, 655-664 (1999)

7. A. Laviano, C. Cangiano, I. Preziosa, O. Riggio, L. Conversano, A. Cascino, S. Ariemma, F. Rossi Fanelli, Plasma tryptophan levels and anorexia in liver cirrhosis. Int. J. Eat. Disord. 21, 181-186 (1997)

8. H.U. Lautz, O. Selberg, J. Korber, M. Burger, M.J. Muller, Forms of malnutrition in patients with liver cirrhosis. Clin. Invest. 70, 178-186 (1992)

9. M. Merli, O. Riggio, L. Dally, Does malnutrition affect survival in cirrhosis? Policentrica Italiana Nutrizione Cirrosi (PINC). Hepatology 23, 1041-1046 (1996)

10. M. Kojima, H. Hosoda, Y. Date, M. Nakazato, H. Matsuo, K. Kangawa, Ghrelin is a growth hormone-releasing acylated peptide from stomach. Nature 402, 656-658 (1999)

11. F. Cordido, A. Peñalva, C. Dieguez, F. Casanueva, Massive growth hormone (GH) discharge in obese subjects after the combined administration of Growth Hormone releasing hormone and GHRP-6: evidence for a marked somatotroph secretory capability in obesity. J. Clin. Endocrinol. Metab. 76, 819-823 (1993)

12. P. Alvarez, L. Isidro, J. Garcia-Buela, J. Leal-Cerro, F. Broglio, F. Tassone, E. Ghigo, C. Dieguez, F.F. Casanueva, F. Cordido, Marked GH secretion after ghrelin alone or combined with GH-releasing hormone (GHRH) in obese patients. Clin. Endocrinol. 61, 250-255 (2004)

13. A.J. van der Lely, M. Tschop, M.L. Heiman, E. Ghigo, Biological, physiological, pathophysiological, and pharmacological aspects of ghrelin. Endocr. Rev. 25, 426-457 (2004)

14. M. Tschop, D.L. Smiley, M.L. Heiman, Ghrelin induces adiposity in rodents. Nature 407, 908-909 (2000)

15. M. Nakazato, N. Murakami, Y. Date, M. Kojima, H. Matsuo, K. Kangawa, S. Matsukura, A role for ghrelin in the central regulation of feeding. Nature 409, 194-198 (2001)

16. Y. Shuto, T. Shibasaki, A. Otagiri, H. Kuriyama, H. Ohata, H. Tamura, J. Kamegai, H. Sugihara, S. Oikawa, I. Wakabayashi, Hypothalamic growth hormone secretagogue receptor regulates growth hormone secretion, feeding and adiposity. J. Clin. Invest. 109, 1429-1436 (2002)

17. A.M. Wren, L.J. Seal, M.A. Cohen, A.E. Brynes, G.S. Frost, K.G. Murphy, Ghrelin enhances appetite and increases food intake in humans. J. Clin. Endocrinol. Metab. 86, 5992-5998 (2001)

18. D.E. Cummings, K. Clement, J.Q. Purnell, C. Vaisse, K.E. Foster, R.S. Frayo, M.W. Schwartz, A. Basdevant, D.S. Weigle, Elevated plasma ghrelin levels in Prader-Willi syndrome. Nat. Med. 8, 643-644 (2002)

19. D.E. Cummings, D.S. Weigle, R.S. Frayo, P.A. Breen, M.K. Ma, E.P. Dellinger, J.Q. Purnell, Plasma ghrelin levels after diet-induced weight loss or gastric bypass surgery. N. Engl. J. Med. 346, 1623-1630 (2002)

20. M. Tschop, C. Weyer, P.A. Tataranni, V. Devanarayan, E. Ravussin, M.L. Heiman, Circulating ghrelin are decreased in human obesity. Diabetes 50, 707-709 (2001)

21. A.M. Haqq, I.S. O'Farooqi, S. Rahilly, D.D. Stadler, R.G. Rosenfeld, K.L. Prat, S.H. LaFranchi, J.Q. Purnell, Serum ghrelin levels are inversely correlated with body mass index, age, and insulin concentrations in normal children and are markedly increased in Prader-Willi syndrome. J. Clin. Endocrinol. Metab. 88, 174-178 (2003) 
22. G. Muccioli, M. Tschop, M. Papotti, R. Deghenghi, M. Heiman, E. Ghigo, Neuroendocrine and peripheral activities of ghrelin: implications in metabolism and obesity. Eur. J. Pharmacol. 440, 235-254 (2002)

23. B. Otto, U. Cuntz, E. Fruehauf, R. Wawarta, C. Folwaczny, R.L. Riepl, M.L. Heiman, P. Lehnert, M. Fichter, M. Tschöp, Weight gain decreases elevated plasma ghrelin concentrations of patients with anorexia nervosa. Eur. J. Endocrinol. 145, 669-673 (2001)

24. O. Ukkola, Ghrelin and insulin metabolism. Eur. J. Clin. Invest. 33, 183-185 (2003)

25. A. Asakawa, A. Inui, T. Kaga, G. Katsuura, M. Fujimiya, M.A. Fujino, M. Kasuga, Antagonism of ghrelin receptor reduces food intake and body weight gain in mice. Gut 52, 947-952 (2003)

26. T. McLaughlin, F. Abbasi, C. Lamendola, R.S. Frayo, D.E. Cummings, Plasma ghrelin concentrations are decreased in insulin-resistant obese adults relative to equally obese insulin-sensitive controls. J. Clin. Endocrinol. Metab. 89, 1630-1635 (2004)

27. T. Shiiya, M. Nakazato, M. Mizuta, Y. Date, M.S. Mondal, M. Tanaka, S. Nozoe, H. Hosoda, K. Kangawa, S. Matsukura, Plasma ghrelin levels in lean and obese humans and the effect of glucose on ghrelin secretion. J. Clin. Endocrinol. Metab. 87, 240-244 (2002)

28. D.E. Cummings, J.Q. Purnell, R.S. Frayo, K. Schmidova, B.E. Wisse, D.S. Weigle, A preprandial rise in plasma ghrelin levels suggests a role in meal initiation in humans. Diabetes 50, 1714-1719 (2001)

29. M. Kojima, K. Kangawa, Ghrelin: structure and function. Physiol. Rev. 85, 495-522 (2005)

30. M. Hotta, R. Ohwada, H. Katakami, T. Shibasaki, N. Hizuka, K. Takano, Plasma levels of intact and degraded ghrelin and their responses to glucose infusion in anorexia nervosa. J. Clin. Endocrinol. Metab. 89, 571-5707 (2004)

31. E. Kalaitzakis, I. Bosaeus, L. Ohman, E. Björnsson, Altered postprandial glucose, insulin, leptin, and ghrelin in liver cirrhosis: correlations with energy intake and resting energy expenditure. Am. J. Clin. Nutr. 85, 808-815 (2007)

32. H. Ataseven, I.H. Bahcecioglu, N. Kuzu, M. Yalniz, S. Celebi, A. Erensoy, B. Ustundag, The levels of ghrelin, leptin, TNF-alpha, and IL-6 in liver cirrhosis and hepatocellular carcinoma due to HBV and HDV infection. Mediators Inflamm. 2006, 78380-78385 (2006)

33. H. Takahashi, A. Kato, K. Onodera, K. Suzuki, Fasting plasma ghrelin levels reflect malnutrition state in patients with liver cirrhosis. Hepatol. Res. 34, 117-123 (2006)

34. M. Breidert, T.F. Zimmermann, R. Schneider, G. Ehninger, G. Brabant, Ghrelin/Leptin-imbalance in patients with primary biliary cirrhosis. Exp. Clin. Endocrinol. Diabetes 112, 123-126 (2004)

35. F. Tacke, G. Brabant, E. Kruck, R. Horn, P. Schöffski, H. Hecker, M.P. Manns, C. Trautwein, Ghrelin in chronic liver disease. J. Hepatol. 38, 447-454 (2003)

36. M. Granado, A.I. Martín, M. López-Menduiña, A. López-Calderón, M.A. Villanúa, GH-releasing peptide-2 administration prevents liver inflammatory response in endotoxemia. Am. J. Physiol. Endocrinol. Metab. 294, E131-E141 (2008)

37. S.O. Işeri, G. Sener, B. Saglam, F. Ercan, N. Gedik, B.C. Yeğen, Ghrelin alleviates biliary obstruction-induced chronic hepatic injury in rats. Regul. Pept. 146, 73-79 (2008)

38. O. Kasımay, S.O. Işeri, A. Barlas, D. Bangir, C. Yeğen, S. Arbak, B.C. Yeğen, Ghrelin ameliorates pancreaticobiliary inflammation and associated remote organ injury in rats. Hepatol. Res. 36, 11-19 (2006)

39. H. Hosoda, M. Kojima, T. Mizushima, S. Shimizu, K. Kangawa, Structural divergence of human ghrelin. Identification of multiple ghrelin-derived molecules produced by post-translational processing. J. Biol. Chem. 278, 64-70 (2003)

40. X. Zhu, Y. Cao, K. Voodg, D.F. Steiner, On the processing of proghrelin to ghrelin. J. Biol. Chem. 281, $38867-$ 38870 (2006)

41. M.A. Bednarek, S.D. Feighner, S.S. Pong, K.K. McKee, D.L. Hreniuk, M.V. Silva, V.A. Warren, A.D. Howard, L.H. Van Der Ploeg, J.V. Heck, Structure-function studies on the new growth hormone-releasing peptide, ghrelin: minimal sequence of ghrelin necessary for activation of growth hormone secretagogue receptor 1a. J. Med. Chem. 43, 4370-4376 (2000)

42. P. Cassoni, M. Papotti, C. Ghe, F. Catapano, A. Sapino, A. Graziani, R. Deghenghi, T. Reissmann, E. Ghigo, G. Muccioli, Identification, characterization, and biological activity of specific receptors for natural (ghrelin) and synthetic growth hormone secretagogues and analogs in human breast carcinomas and cell lines. J. Clin. Endocrinol. Metab. 86, 1738-1745 (2001)

43. I. Bedendi, G. Alloatti, A. Marcantoni, D. Malan, F. Catapano, C. Ghe, R. Deghenghi, E. Ghigo, G. Muccioli, Cardiac effects of ghrelin and its endogenous derivatives des-octanoyl ghrelin and des-Gln14-ghrelin. Eur. J. Pharmacol. 476, 87-95 (2003)

44. N.M. Thompson, D.A. Gill, R. Davies, N. Loveridge, P.A. Houston, I.C. Robinson, T. Wells, Ghrelin and desoctanoyl ghrelin promote adipogenesis directly in vivo by a mechanism independent of the type 1a growth hormone secretagogue receptor. Endocrinology 145, 234-242 (2004)

45. K. Toshinai, H. Yamaguchi, Y.X. Sun, R.G. Smith, A. Yamanaka, T. Sakurai, Y. Date, M.S. Mondal, T. Shimbara, T. Kawagoe, N. Murakami, M. Miyazato, K. Kangawa, M. Nakazato, Des-acyl ghrelin induces food intake by a mechanism independent of the growth hormone secretagogue receptor. Endocrinology 147, 23062314 (2006)

46. C. Gauna, P.J. Delhanty, M.O. van Aken, J.A. Janssen, A.P. Themmen, L.J. Hofland, M. Culler, F. Broglio, E. Ghigo, A.J. van der Lely, Unacylated ghrelin is active on the INS-1E rat insulinoma cell line independently of the growth hormone secretagogue receptor type $1 \mathrm{a}$ and the corticotropin releasing factor 2 receptor. Mol. Cell. Endocrinol. 251, 103-111 (2006) 
47. C. Gauna, F.M. Meyler, J.A. Janssen, P.J.D. Delhanty, T. Abribat, P. van Koetsveld, L.J. Hofland, F. Broglio, E. Ghigo, A.J. van der Lely, Administration of acylated ghrelin reduces insulin sensitivity, whereas the combination of acylated plus unacylated ghrelin strongly improves insulin sensitivity. J. Clin. Endocrinol. Metab. 89, 50355042 (2004)

48. M. Tschöp, R. Wawarta, R.L. Riepl, S. Friedrich, M. Bidlingmaier, R. Landgraf, C. Folwaczny, Post-prandial decrease of circulating human ghrelin levels. J. Endocrinol. Invest. 24, RC19-RC21 (2001)

49. K.E. Foster-Schubert, J. Overduin, C.E. Prudom, J. Liu, H.S. Callahan, B.D. Gaylinn, M.O. Thorner, D.E. Cummings, Acyl and total ghrelin are suppressed strongly by ingested proteins, weakly by lipids, and biphasically by carbohydrates. J. Clin. Endocrinol. Metab. 93, 1971-1979 (2008)

50. J. Liu, C.E. Prudom, R. Nass, S.S. Pezzoli, M.C. Oliveri, M.L. Johnson, P. Veldhuis, D.A. Gordon, A.D. Howard, D.R. Witcher, H.M. Geysen, B.D. Gaylinn, M.O. Thorner, Novel ghrelin assays provide evidence for independent regulation of ghrelin acylation and secretion in healthy young men. J. Clin. Endocrinol. Metab. 93, 1980-1987 (2008)

51. G. Marchesini, U. Pagotto, E. Bugianesi, R. De Iasio, R. Manini, E. Vanni, R. Pasquali, N. Melchionda, M. Rizzetto, Low ghrelin concentrations in nonalcoholic fatty liver disease are related to insulin resistance. J. Clin. Endocrinol. Metab. 88, 5674-5679 (2003)

52. G. Murdolo, P. Lucidi, C. Di Loreto, N. Parlanti, A. De Cicco, C. Fatone, C.G. Fanelli, G.B. Bolli, F. Santeusanio, P. De Feo, Insulin is required for prandial ghrelin suppression in humans. Diabetes 52, 2923-2927 (2003)

53. D.E. Flanagan, M.L. Evans, T.P. Monsod, F. Rife, R.A. Heptulla, W.V. Tamborlane, R.S. Sherwin, The influence of insulin on circulating ghrelin. Am. J. Physiol. Endocrinol. Metab. 284, E313-E316 (2003)

54. W.A.M. Blom, A. Stafleu, C. de Graaf, F.J. Kok, G. Schaafsma, H.F. Hendriks, Ghrelin response to carbohydrate-enriched breakfast is related to insulin. Am. J. Clin. Nutr. 81, 367-375 (2005)

55. A. Caixas, C. Bashore, W. Nash, X. Pi-Sunyer, B. Laferrere, Insulin, unlike food intake, does not suppress ghrelin in human subjects. J. Clin. Endocrinol. Metab. 87, 1902-1905 (2002)

56. G. Schaller, A. Schmidt, J. Pleiner, W. Woloszczuk, M. Woltz, A. Luger, Plasma ghrelin concentrations are not regulated by glucose or insulin: a double-blind, placebo-controlled crossover clamp study. Diabetes 5, 16-20 (2003)

57. R. Nass, L.S. Farhy, J. Liu, C.E. Prudom, M.L. Johnson, P. Veldhuis, S.S. Pezzoli, M.C. Oliveri, B.D. Gaylinn, H.M. Geysen, M.O. Thorner, Evidence for acyl-ghrelin modulation of growth hormone release in the fed state. J. Clin. Endocrinol. Metab. 93, 1988-1994 (2008)

58. F.M. Van der Toorn, J.A. Janssen, W.W. de Herder, F. Broglio, E. Ghigo, A.J. van der Lely, Central ghrelin production does not substantially contribute to systemic ghrelin concentration: a study inn two subjects with active acromegaly. Eur. J. Endocrinol. 147, 195-199 (2002)

59. A.L. Barkan, E.V. Dimaraki, S.K. Jessup, K.V. Symons, M. Ermolenko, C.A. Jaffe, Ghrelin secretion in humans is sexually dimorphic, suppressed by somatostatin, and not affected by the ambient growth hormone levels. J. Clin. Endocrinol. Metab. 88, 2180-2184 (2003)

60. Z. Jarkovska, M. Rosicka, J. Marek, V. Hana, V. Weiss, V. Justova, Z. Lacinová, M. Haluzík, M. Krsek, Plasma levels of total and active ghrelin in acromegaly and growth hormone deficiency. Physiol. Res. 55, 175-181 (2006)

61. M.L. Isidro, R. Nemiña, J. Garcia-Buela, S. Sangiao-Alvarellos, F. Cordido, Effect of oral glucose on acylated and total ghrelin secretion in acromegalic patients. Neuro Endocrinol. Lett. 28, 596-603 (2007)

62. V. Cappiello, C. Ronchi, P.S. Mospurgo, P. Epaminonda, P. Beck-Peccoz, A. Spada, Circulating ghrelin levels in basal conditions and during glucose tolerance test in acromegalic patients. Eur. J. Endocrinol. 147, 189-194 (2002)

63. P.U. Freda, C.M. Reyes, I.M. Conwell, R.E. Sundeen, S.L. Wardlaw, Serum ghrelin levels in acromegaly: effects of surgical and long-acting octreotide therapy. J. Clin. Endocrinol. Metab. 88, 2037-2044 (2003)

64. J. Kozakowski, M. Rabijewski, W. Zgliczynski, Decreased in serum ghrelin levels in patients with acromegaly normalize after successful surgical treatment. Endokrynol. Pol. 56, 862-870 (2005)

65. E.T. Vestergaard, R. Dall, K.H. Lange, M. Kjaer, J.S. Christiansen, J.O. Jorgensen, The ghrelin response to exercise before and after growth hormone administration. J. Clin. Endocrinol. Metab. 92, 297-303 (2007)

66. H.J. Kim, L. Sangyeoup, T.W. Kim, H.H. Kim, T.Y. Jeon, Y.S. Yoon, S.W. Oh, H. Kwak, J.G. Lee, Effects of exercise-induced weight loss on acylated and unacylated ghrelin in overweight children. Clin. Endocrinol. 68, 416-422 (2008)

67. M. Perez-Fontán, F. Cordido, A. Rodriguez-Carmona, J. Peteiro, R. Garcia-Naveiro, J. Garcia-Buela, Plasma ghrelin levels in patients undergoing haemodialysis and peritoneal diálysis. Nephrol. Dial. Transplant. 19, 20952100 (2004)

68. M. Perez-Fontán, F. Cordido, A. Rodriguez-Carmona, R. Garcia-Naveiro, M.L. Isidro, P. Villaverde, J. GarciaBuela, Acute plasma ghrelin and leptin responses to oral feeding or intraperitoneal hypertonic glucose-based dialysate in patients with chronic renal failure. Kidney Int. 2005(68), 2877-2885 (2005)

69. M. Pérez-Fontán, F. Cordido, A. Rodríguez-Carmona, M. Penín, H. Díaz-Cambre, A. López-Muñiz, S. SangiaoAlvarellos, J. García-Buela, Short-term regulation of peptide YY secretion by a mixed meal or peritoneal glucose-based dialysate in patients with chronic renal failure. Nephrol. Dial. Transplant. 23, 3696-3703 (2008)

70. D.R. Matthews, J.P. Hosker, A.S. Rudenski, D.B. Naylor, D.F. Treacher, R.C. Turner, Homeostasis model assessment: insulin resistance and beta-cell function from fasting plasma glucose and insulin concentrations in man. Diabetología 28, 412-419 (1985) 